\title{
Potential factors associated with knee pain in cyclists: a systematic review
}

\author{
Rodrigo Rico Bini \\ Alice Flores Bini \\ La Trobe Rural Health School, La \\ Trobe University, Flora Hill Campus, \\ Bendigo, VIC, Australia
}

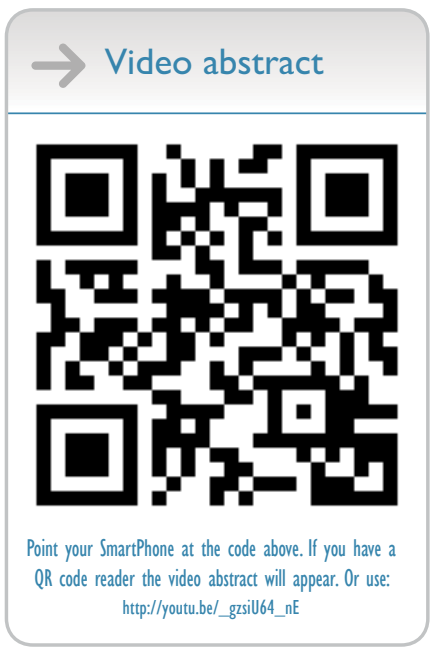

Correspondence: Rodrigo Rico Bini La Trobe Rural Health School, La Trobe University, Flora Hill Campus, Bendigo, VIC 3550, Australia

Tel +6I 354447466

Email r.bini@latrobe.edu.au
This article was published in the following Dove Press journal: Open Access Journal of Sports Medicine

\begin{abstract}
The potential factors associated with overuse injuries and pain in cyclists that are supported by evidence remain unclear. Our study aimed at assessing, using a systematic search of the most updated evidence, the main factors related to overuse knee-related pain and/or injuries in cyclists. The search assessed any potential mechanism related to knee pain or injury that could be used in the clinical practice. Databases were searched (i.e., PubMed, Scopus, Web of Science, and EBSCO). Studies were included if they presented results from original studies. They had to include, preferably but not limited to, recreational and/or competitive cyclists with or without knee pain. Quality of articles was assessed. Eleven articles were deemed eligible for full text appraisal. Studies involved generally the assessment of biomechanical outcomes associated with knee pain in cyclists. Overall, studies showed that cyclists with knee pain present larger knee adduction and larger ankle dorsiflexion and differences in activation for hamstrings and quadriceps muscles. Unclear results were observed for knee moments and no differences were observed for knee flexion angle, tibiofemoral and patellofemoral forces. It is important to state that varied types of knee pain were mixed in most studies, with 2 focused on anterior-related pain. Cyclists with overuse-related pain or injuries on their knees presented an increased medial projection of their knees and an altered activation of the Vastus Medialis and Vastus Lateralis muscles. However, this limited evidence is based on retrospective studies comparing cyclists with and without pain, which limits the conclusion on how cyclists develop knee pain and what are the main options for treatment of knee pain.
\end{abstract}

Keywords: injury, cycling, overuse, biomechanics

\section{Introduction}

Cycling is an appealing mode of locomotion and the adherence with cycling has increased progressively through the years. Due to the popularity of cycling and increase in pedaling time, injuries are very common in this sport. Although traumatic injuries are high in incidence in cyclists, ${ }^{1,2}$ overuse injuries are more difficult to anticipate because of their multifactorial nature. The knee joint is one of the most affected body parts by overuse injuries. ${ }^{1,2}$ Several epidemiological studies have shown that experiencing knee pain or knee injuries ranges between $14.8 \%$ and $33 \%$ in cyclists involved in long-duration pedaling. ${ }^{3-9}$ Bakkes et $\mathrm{al}^{4}$ presented a study where 902 cyclists were questioned at the end of the Burger-Sanlam 100/50 km race to identify injuries in the previous year. They found that $61 \%$ of cyclists did not have an injury in the previous year while $29 \%$ reported suffering from knee pain, suggesting that the long-duration cycling activity could have triggered their knee pain. Dannenberg et $\mathrm{al}^{8}$ in a prospective study of 1638 recreational cyclists involved in the Cycle Across 
Maryland tour observed 76 overuse injuries, with the knee joint being the most affected body part for pain. Althunyan et $\mathrm{al}^{3}$ showed that the prevalence of knee pain was $27.6 \%$ for amateur cyclists and $15.9 \%$ for professional cyclists, and they suggested that the type of bicycle could be an important factor in knee pain.

Different types of studies have been conducted to assess the possible reasons for pain and injuries due to cycling. For instance, the association with other sports activities, ${ }^{3}$ bicycle misalignment, ${ }^{4}$ inexperience or lack of pre-ride conditioning,${ }^{8}$ and long distances ride ${ }^{10}$ were among the suggested triggers for knee pain. Dettori and Norvel, ${ }^{11}$ discussed some possible mechanisms for non-traumatic injuries and prevention plan. As an example, for patellofemoral inflammation, the saddle could be too low and/or too far forward and most authors have encouraged to follow preventive adjustments, like proper saddle adjustment, the use of orthotics, cleat adjustment, and reduction in gear ratio (especially early in the season), among others. ${ }^{1,2,12,13}$ However, only a few of these strategies have been tested experimentally, and most of the advocated recommendations lack of solid evidence that could be important in preventing injuries.

Sabeti-Aschraf et al $^{14}$ investigated 169 competitive mountain bikers and correlated their injury occurrence with the configuration of their bicycles. They found that 87 had overuse injuries after a race (Babenberger Trophy) and observed a significant correlation between inadequate saddle-pedal distance and knee pain $(p<0.04)$. They concluded that bicycle adjustments have a direct impact on the incidence of overuse injuries in the competitive mountain bike cyclist. Conversely, Dahlquist et $\mathrm{al}^{7}$ declared in their study that flexibility, strength, and bike fit measures did not predict injury and concluded that injury risk and prevention strategies need additional studies. There are a minimum of 20 review articles published suggesting how to prevent and treat knee pain and injuries despite lack evidence supporting the current advocated practices. With this in mind, the determinants of overuse injuries and pain in cyclists that are supported by evidence remain unclear.

Our study aimed to assess the potential factors associated with overuse knee-related pain and/or injuries in cyclists using a systematic search of the most updated evidence. The search intended to assess any potential mechanism related to knee pain or injury that could be used in the clinical practice. The findings from this search could then provide support for the assessment of key outcomes that could be used during clinical analysis of cyclists and/or bike fitting.

\section{Materials and methods \\ Data search strategy}

Databases were searched (i.e., PubMed, Scopus, Web of Science, and EBSCO) using the following keywords with Boolean operators: "knee", "injur*”, "pain", "cycl*”. Full details of articles were exported to EndNote (Thomson Reuters, New York, USA) to allow for exclusion of duplicates and assessment of articles' titles and abstract.

\section{Inclusion and exclusion criteria}

Studies were included if they presented results from original (i.e., experimental) studies, which resulted in the removal of review articles and epidemiological studies. Studies had to include, preferably, but not limited to, recreational and/or competitive cyclists with or without knee pain. We opted for including studies that did not assess cyclists with injury or pain on the knees but assessed injury-related outcomes that could potentially explain the reason for why cyclists have knee pain. The reason for this option was also an attempt to expand the understanding on what could trigger knee pain in cyclists (e.g., excessive compressive force at the patellofemoral joint). In addition to that was the potential reduced number of experimental studies assessing the determinants of knee pain in cyclists that sustained cycling as an exercise and/or training. However, due to the aim of our study, articles that assessed non-cyclists with knee injuries potentially not related to bicycle pedaling were removed. Studies that had focus on triathletes or any combined training mode were also excluded due to potential carryover effects from other training activities (e.g., swimming and running). Finally, articles that assessed traumatic (acute) injuries in cycling were also excluded.

\section{Quality assessment}

Quality of articles was assessed using a scale described by Agresta and Brown, ${ }^{15}$ which comprised 16 elements (Table 1) worth 20 points in total. The items involved study design (worth 5 points), experimental control, study participants, methodology, and outcomes. Studies were then ranked as high (14-20 points), medium (7-13 points), and low quality (1-6 points). Articles were ranked simultaneously by both authors and disagreement was resolved to reach consensus.

\section{Results}

A total of 559 article titles were retrieved from the databases. Removal of duplicates resulted in 285 articles for assessment of title and abstract, which also led to the removal of 274 


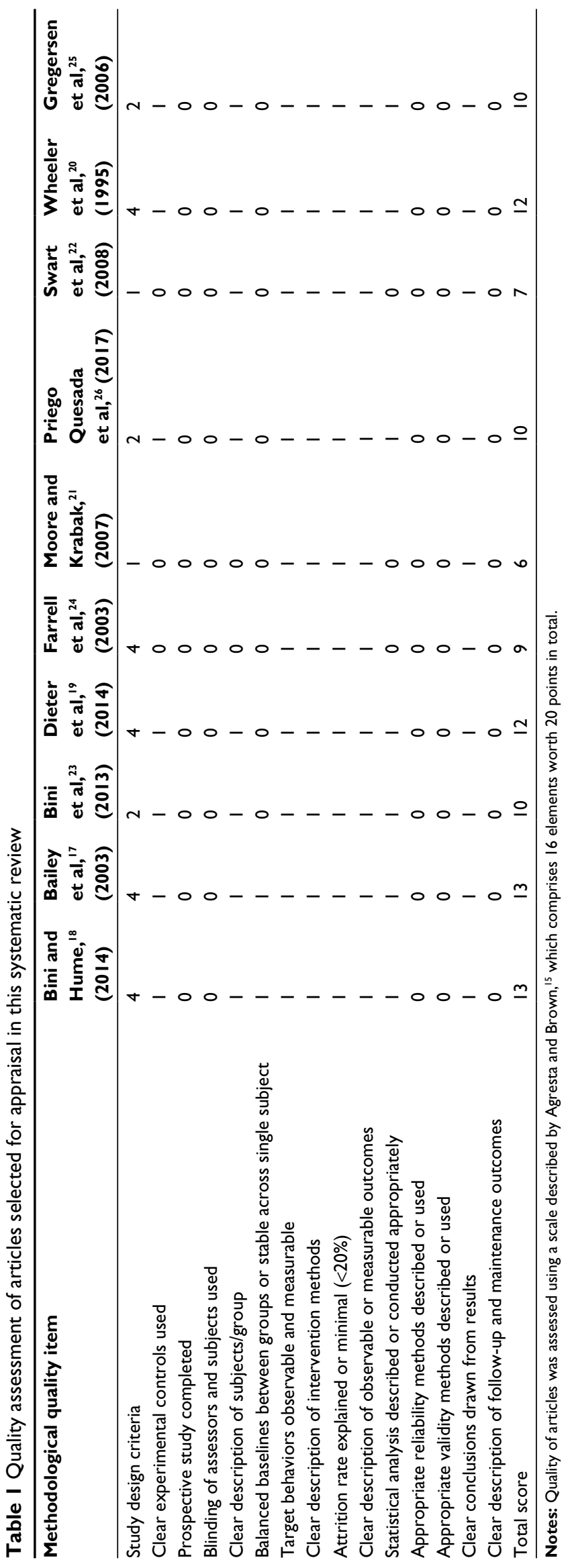

articles not related to the aim of this study. The removal of articles from the assessment of titles and abstracts encompassed the inclusion/exclusion criteria for the study. Fortyone articles were then assessed and separated in 3 main categories. Twenty review articles were not assessed but will be referred in the "Discussion" section (i.e., review articles). Ten studies with focus on the epidemiology of overuse injuries were also separated to be discussed in terms of the incidence of injuries in cycling. Eleven articles were deemed eligible for full text appraisal but 1 was not assessed due to difficulties in retrieving the full text and the original language being German ${ }^{16}$ (Figure 1). Results are presented in tables with information on sample size, study design, methods, outcomes, and main findings for each study.

Studies involved generally the assessment of biomechanical outcomes associated with knee pain in cyclists. Four studies ${ }^{17-20}$ involved the assessment of cyclists (mostly recreational) reporting knee pain related to bicycle pedaling or providing medical evidence for knee pain (e.g., MRI). Two articles involved case studies of individual cyclists who had cycling-related knee pain. ${ }^{21,22}$ One study ${ }^{21}$ did not assess bicycle pedaling and was limited to clinical description of symptoms and imaging scan. Four studies ${ }^{23-26}$ did not assess cyclists with injury or pain on the knees but assessed injuryrelated outcomes that could potentially explain the reason for why cyclists develop knee pain (Table 2).

Among the outcomes, authors reported kinematics (e.g., knee flexion angle), kinetics (e.g., knee joint moments), muscular activation (e.g., surface electromyography), and perceived comfort gathered from stationary cycling trials and others acquired from various tasks (e.g., isokinetic dynamometry).

Quality assessment indicated that only 1 study was ranked as low quality ${ }^{22}$ while others were of medium quality. The main reason for the moderate quality of studies is related to the absence of a prospective design, lack of blinding for the assessors, lack of provision of reliability, and validity of the outcome measures, and no follow-up assessment being conducted. Therefore, the design of all studies was limited to cross-sectional retrospective (Table 1).

Overall, studies showed that cyclists with knee pain presented larger knee adduction and larger ankle dorsiflexion ${ }^{17}$ and differences in activation for hamstrings and quadriceps muscles (Table 2). ${ }^{19}$ Unclear results were observed for knee moments ${ }^{20}$ and no differences were observed for knee flexion angle, tibiofemoral and patellofemoral forces. ${ }^{18} \mathrm{It}$ is important to state that varied types of knee pain were mixed in most studies, with 2 focusing on anterior-related pain. ${ }^{17,19}$ 


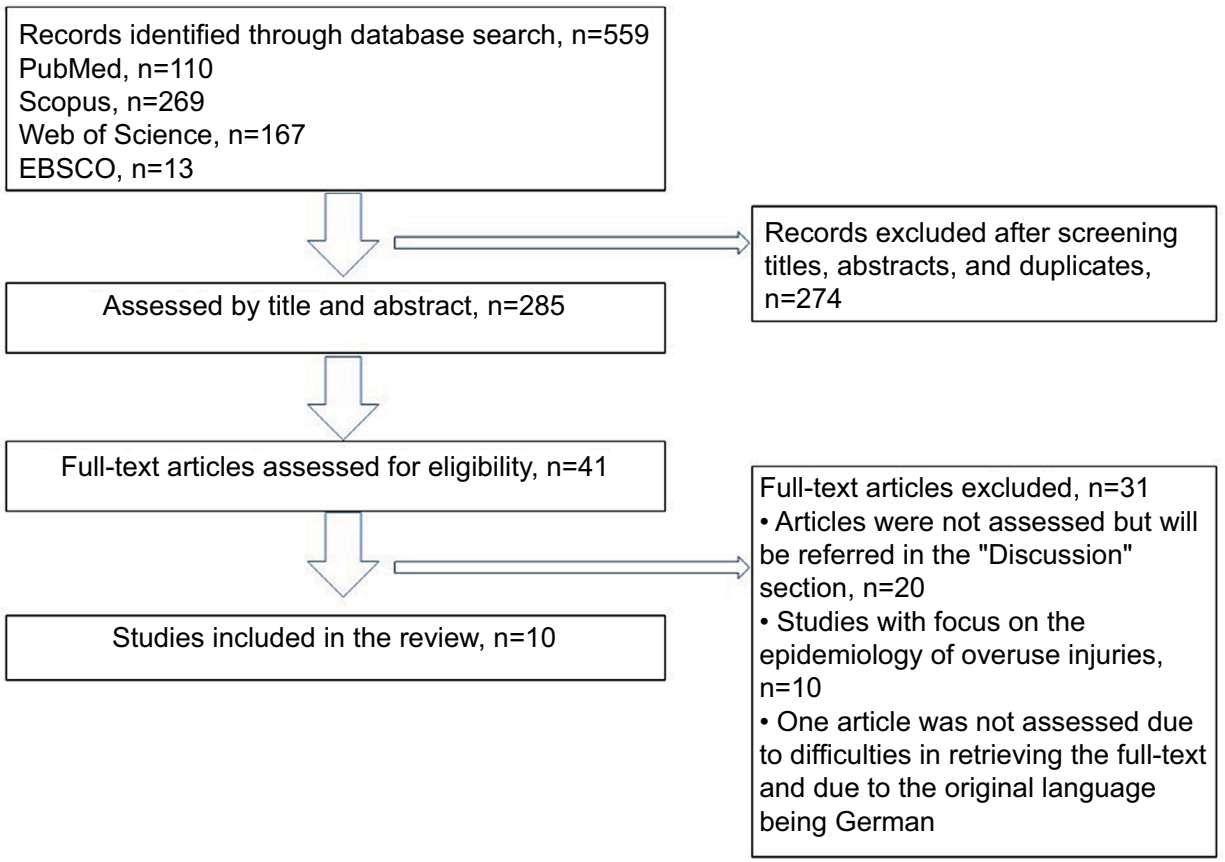

Figure I Flow diagram of the search methods used in this review.

\section{Discussion}

This systematic review of the literature intended to assess the potential factors associated with overuse knee injuries and knee pain in cyclists. After a careful search on the main databases related to health and sports sciences, we observed that there is limited evidence on the potential mechanisms related to overuse-related pain or injury. Surprisingly, 20 narrative reviews covering, but not limited to, knee pain in cycling were found, even though the evidence is scarce in terms of the determinants of overuse knee injuries, which limits the options for prevention and treatment.

Some differences were observed when comparing cyclists with and without knee pain. Cyclists with knee pain presented a medial projection of the lower limb during the power phase of cycling (from 12 to 60 'clock positions of the crank) associated with an increased ankle dorsiflexion. ${ }^{17}$ Although a larger medial projection of the femur in relation to the patella could lead to a reduced contact area for the patellofemoral joint, ${ }^{27}$ this may be an adaptation to injury due to the retrospective nature of findings from Bailey et al. ${ }^{17}$ The delayed offset of vastus lateralis and earlier offset of vastus medialis observed by Dieter et a ${ }^{19}$ in cyclists with knee pain could also be a consequence from the medial projection of the femur. However, no data have been found in this issue when uninjured cyclists enforced a medial projection of their knees. In addition, no evidence on the control from hip adductors and/or abductors has been shown, which could help determining the rationale for the medial projection of the femur. In runners, a delayed onset of hip abductors has been associated with knee pain, ${ }^{28}$ which provides a potential link between a delayed activation of hip abductors and the medial knee projection.

An alternative scenario would involve a differential activation of hip adductor (e.g., adductor magnus) and hip external rotators (e.g., gluteus maximus). This differential activation, in favor of the hip adductors, could lead to an enhanced medial projection of the knee. Bini et $\mathrm{al}^{29}$ observed that an enforced hip adduction (commonly observed in time trial and track cycling) leads to an increased activation of hip adductors and larger forces applied to the pedals. ${ }^{30}$ Interestingly, Ericson et $\mathrm{l}^{31}$ observed that an enforced medial projection of the knees also leads to an increased lateral shear force at the knee joint, which could be expected to trigger knee injuries. However, no evidence has been provided on this link. Although the relationship between differential activation from hip muscles is lacking, clinicians could assess the ranges of motion and mobility for the hip joint of cyclists to evaluate whether changes in muscle force and mobility could be triggering the excessive medial projection of the knees.

Even though low saddle height has been previously related to increased knee loads (which could trigger knee pain and injury), cyclists with overuse-related pain did not present lower saddle heights or increased patellofemoral 
Table 2 Summary of findings from studies selected for appraisal in this systematic review

\begin{tabular}{|c|c|c|c|c|}
\hline $\begin{array}{l}\text { Authors } \\
\text { (year) }\end{array}$ & $\begin{array}{l}\text { Sample size, } \\
\text { participants with } \\
\text { knee pain }\end{array}$ & Protocol & Outcomes & Main results \\
\hline $\begin{array}{l}\text { Bini and } \\
\text { Hume, }{ }^{18}(2014)\end{array}$ & $\begin{array}{l}24 \text { recreational } \\
\text { cyclists, } 8 \text { with } \\
\text { knee pain }\end{array}$ & $\begin{array}{l}\text { Pedaling with } 243 \pm 78 \mathrm{~W} \\
\text { at } 90 \pm 2 \text { rpm in } 4 \text { saddle } \\
\text { heights (preferred, low, } \\
\text { high, and optimum). }\end{array}$ & $\begin{array}{l}\text { Knee flexion angles (3 } \\
\text { and } 6 \text { o'clock), PFC, } \\
\text { TFC, TFS forces }\end{array}$ & $\begin{array}{l}\text { No differences between groups for any of the } \\
\text { outcomes. }\end{array}$ \\
\hline $\begin{array}{l}\text { Bailey et al, }{ }^{17} \\
(2003)\end{array}$ & $\begin{array}{l}24 \text { cyclists, } 10 \text { with } \\
\text { history of knee } \\
\text { pain }\end{array}$ & $\begin{array}{l}\text { Pedaling with } 200 \pm 10 \mathrm{~W} \text { at } \\
90 \mathrm{rpm} \text {. }\end{array}$ & $\begin{array}{l}\text { Knee flexion and } \\
\text { adduction angles, ankle } \\
\text { dorsi/plantar flexion, } \\
\text { shank adduction velocity. }\end{array}$ & $\begin{array}{l}\text { Larger knee adduction }\left(1.9^{\circ}\right) \text { and larger dorsi } \\
\text { flexion }\left(4.9^{\circ}\right) \text { for cyclists with knee pain. }\end{array}$ \\
\hline $\begin{array}{l}\text { Bini et al, }{ }^{23} \\
(20 \mid 3)\end{array}$ & $\begin{array}{l}2 \text { I competitive } \\
\text { cyclists, none with } \\
\text { knee pain }\end{array}$ & $\begin{array}{l}\text { Pedaling with } 309 \pm 48 \\
\text { W at } 90 \pm 2 \text { rpm in three } \\
\text { positions on the saddle } \\
\text { (preferred, forward, } \\
\text { backward). }\end{array}$ & $\begin{array}{l}\text { Knee flexion angles ( } 3 \\
\text { and } 6 \text { o'clock), PFC, } \\
\text { TFC, TFS forces }\end{array}$ & $\begin{array}{l}\text { Large increases in TFS force in the backward } \\
\text { position compared to the preferred (19\%) and } \\
\text { forward ( } 26 \%) \text {. Knee flexion angle increased at } \\
\text { the forward compared to the backward saddle } \\
\text { position }(22 \%-36 \%) \text {. No change for other } \\
\text { outcomes. }\end{array}$ \\
\hline $\begin{array}{l}\text { Dieter et al, }{ }^{19} \\
(2014)\end{array}$ & $\begin{array}{l}\text { I7 cyclists, } 7 \text { with } \\
\text { patellofemoral pain }\end{array}$ & $\begin{array}{l}\text { Pedaling with RPE of } 14 \\
\text { points (max 20) at } 90 \\
\text { rpm. Work rate was not } \\
\text { measured. }\end{array}$ & $\begin{array}{l}\text { Amplitude, onset and } \\
\text { offset of activation of } \\
\text { vastus medialis, vastus } \\
\text { lateralis, semitendinous } \\
\text { and biceps femoris. Knee } \\
\text { angles for onset and } \\
\text { offset of muscles were } \\
\text { determined. }\end{array}$ & $\begin{array}{l}\text { Activation of biceps femoris was larger and } \\
\text { Semitendinous was smaller for cyclists with pain. } \\
\text { Delayed offset for vastus lateralis and biceps } \\
\text { femoris and delayed onset for semitendinous were } \\
\text { observed for cyclists with pain. Vastus medialis } \\
\text { deactivates first in cyclists with pain, biceps } \\
\text { femoris activates first in cyclists with pain, and } \\
\text { semitendinous deactivates first in cyclists with pain. }\end{array}$ \\
\hline $\begin{array}{l}\text { Farrell et al, }{ }^{24} \\
(2003)\end{array}$ & $\begin{array}{l}\text { Ten athletes (non- } \\
\text { cyclists) without } \\
\text { knee pain }\end{array}$ & $\begin{array}{l}\text { Pedaling with } 280 \mathrm{~W} \text { at } \\
80-90 \mathrm{rpm} .\end{array}$ & $\begin{array}{l}\text { Foot-pedal force (using } \\
\text { shoe insoles) and knee } \\
\text { flexion angle were } \\
\text { measured. }\end{array}$ & $\begin{array}{l}\text { Minimum knee angle of } 33^{\circ} \text { was observed. The } \\
\text { foot-pedal forces during cycling were only } 18 \% \text { of } \\
\text { those occurring during running while the ITB is in } \\
\text { the impingement zone }\left(10^{\circ}-30^{\circ} \text { of flexion). }\right.\end{array}$ \\
\hline $\begin{array}{l}\text { Moore and } \\
\text { Krabak, }{ }^{21} \\
(2007)\end{array}$ & $\begin{array}{l}\text { One cyclist } \\
\text { with history of } \\
\text { a right medial } \\
\text { meniscectomy }\end{array}$ & No exercise undertaken. & MRI of the right knee. & $\begin{array}{l}\text { Aneurysm of the popliteal artery, with posterior } \\
\text { thrombus obstructing } 50 \% \text { of the lumen's } \\
\text { diameter. }\end{array}$ \\
\hline $\begin{array}{l}\text { Priego } \\
\text { Quesada } \\
\text { et al, }{ }^{26}(2017)\end{array}$ & $\begin{array}{l}20 \text { competitive } \\
\text { cyclists without } \\
\text { history of knee } \\
\text { pain }\end{array}$ & $\begin{array}{l}\text { Pedaling at } 50 \% \text { of maximal } \\
\text { power output with } 90 \pm 2 \\
\text { rpm at } 3 \text { saddle heights } \\
\text { (eliciting a knee angle of } \\
20^{\circ}, 30^{\circ} \text {, and } 40^{\circ} \text { ) and } 3 \\
\text { trunk flexion angles }\left(35^{\circ} \text {, }\right. \\
\left.45^{\circ} \text {, and } 55^{\circ}\right) \text {. }\end{array}$ & $\begin{array}{l}\text { Perceived comfort, } \\
\text { subjective fatigue } \\
\text { perception and pain. }\end{array}$ & $\begin{array}{l}\text { Saddle height eliciting a knee flexion angle of } \\
30^{\circ} \text { was the most comfortable. Greater knee } \\
\text { flexion had a negative effect on trunk comfort, } \\
\text { accompanied by greater levels of fatigue and pain } \\
\text { perception in the anterior part of the thigh and } \\
\text { knee. }\end{array}$ \\
\hline $\begin{array}{l}\text { Swart et al, }{ }^{22} \\
(2008)\end{array}$ & $\begin{array}{l}\text { One 32-year-old } \\
\text { male professional } \\
\text { cyclist and former } \\
\text { winner of the Tour } \\
\text { de France with a } \\
\text { 7-year history of } \\
\text { recurrent anterior } \\
\text { knee pain }\end{array}$ & $\begin{array}{l}\text { I. Bilateral isokinetic } \\
\text { testing: knee flexion- } \\
\text { extension at } 60 \text { and } \\
180 \% \text { (concentric); hip } \\
\text { adduction/abduction at } \\
60 \% / \mathrm{s} \text { (concentric). Five } \\
\text { repetitions at } 60 \% \mathrm{~s} \text { and } \\
\text { ten at } 180 \% \text { s. } \\
\text { 2. Pedaling at self-selected } \\
\text { gear at } 65,75,95 \text {, and } \\
\text { I05 rpm. } \\
\text { 3. MRI }\end{array}$ & $\begin{array}{l}\text { From isokinetic: ROM, } \\
\text { peak torque, flexors/ } \\
\text { extensors ratio, bilateral } \\
\text { flexion deficit, bilateral } \\
\text { extension deficit, rate } \\
\text { of fatigue (from } 10 \\
\text { repetitions at } 180^{\circ} / \mathrm{s} \text { ). } \\
\text { From pedaling, } \\
\text { symmetry measure } \\
\text { (bilateral balance in } \\
\text { power output) }\end{array}$ & $\begin{array}{l}\text { Low-grade patellar tendinopathy was observed } \\
\text { from magnetic resonance. Increased eccentric } \\
\text { knee flexion strength of the injured vs. uninjured } \\
\text { leg }(213.4 \mathrm{vs.} 166.3 \mathrm{Nm}) \text {. Mean power balance } \\
(51.0 \% \pm 0.9 \%) \text { was in favor of the injured leg, with } \\
\text { larger values for lower cadences (i.e., } 75 \mathrm{rpm} \\
-51.9 \% \pm 1.5 \%) \text {. }\end{array}$ \\
\hline $\begin{array}{l}\text { Wheeler } \\
\text { et al, }{ }^{20}(1995)\end{array}$ & $\begin{array}{l}34 \text { cyclists, } 7 \text { with } \\
\text { knee pain }\end{array}$ & $\begin{array}{l}\text { Pedaling at } 150,250 \text {, } \\
\text { and } 350 \mathrm{~W} \text { in preferred } \\
\text { cadences ( } 80-105 \mathrm{rpm}) \\
\text { with toe-clips, clipless- } \\
\text { fixed, and clipless-float. }\end{array}$ & $\begin{array}{l}\text { Vertical moment applied } \\
\text { to the pedal. }\end{array}$ & $\begin{array}{l}\text { Internally applied peak moments increased with } \\
\text { work rate. Peak moments were reduced when } \\
\text { using clipless-float. Unclear results for pain. }\end{array}$ \\
\hline
\end{tabular}


Table 2 (Continued)

\begin{tabular}{|c|c|c|c|c|}
\hline $\begin{array}{l}\text { Authors } \\
\text { (year) }\end{array}$ & $\begin{array}{l}\text { Sample size, } \\
\text { participants with } \\
\text { knee pain }\end{array}$ & Protocol & Outcomes & Main results \\
\hline $\begin{array}{l}\text { Gregersen } \\
\text { et al, }{ }^{25}(2006)\end{array}$ & $\begin{array}{l}\text { I } 5 \text { cyclists without } \\
\text { knee pain }\end{array}$ & $\begin{array}{l}\text { Pedaling with } 225 \mathrm{~W} \text { at } \\
90 \mathrm{rpm} \text { using } 5 \text { inversion/ } \\
\text { eversion foot angles } \\
\left(10^{\circ} \text { and } 5^{\circ} \text { of inversion, }\right. \\
\text { neutral, } 5^{\circ} \text { and } 10^{\circ} \text { of } \\
\text { eversion). }\end{array}$ & $\begin{array}{l}\text { Three-dimensional } \\
\text { knee moments (flexor/ } \\
\text { extensor, adductor/ } \\
\text { abductor, varus/valgus). } \\
\text { Activation of vastus } \\
\text { medialis and vastus } \\
\text { lateralis. }\end{array}$ & $\begin{array}{l}\text { The } 10^{\circ} \text { everted angle reduced the peak varus } \\
\text { moment by } 55 \% \text { in relation to the neutral while } \\
\text { the } 10^{\circ} \text { inverted angle increased the peak varus } \\
\text { moment by } 47 \% \text { in relation to the neutral. Peak } \\
\text { internal axial moment decreased by } 53 \% \text { of the } \\
\text { neutral when the foot was } 10^{\circ} \text { everted and } \\
\text { increased by } 88 \% \text { of the neutral when the foot } \\
\text { was } 10^{\circ} \text { inverted. The axial moment was internal } \\
\text { at the neutral position and decreased by } 515 \% \text { of } \\
\text { the neutral becoming external for the } 10^{\circ} \text { everted } \\
\text { angle and increased by } 389 \% \text { of the neutral, } \\
\text { becoming more internal for the } 10^{\circ} \text { inverted } \\
\text { angle. Vastus medialis activation increased relative } \\
\text { to that of the vastus lateralis as the varus moment } \\
\text { decreased. }\end{array}$ \\
\hline $\begin{array}{l}\text { Arnold et al, }{ }^{16} \\
(1988)^{*}\end{array}$ & $\begin{array}{l}104 \text { cyclists, } 24 \\
\text { with femoro- } \\
\text { patellar pain and } \\
28 \text { with other knee } \\
\text { symptoms }\end{array}$ & No exercise undertaken. & $\begin{array}{l}\text { Extensibility of rectus } \\
\text { femoris muscle. }\end{array}$ & $\begin{array}{l}\text { Correlation reported between femoropatellar } \\
\text { pain and reduced extensibility in rectus femoris } \\
\text { muscle was observed. }\end{array}$ \\
\hline
\end{tabular}

Note: *When full text was unavailable.

Abbreviations: PFC, patellofemoral compressive; ROM, range of motion; RPE, rate of perceived exertion; rpm, revolutions per minute; TFC, tibiofemoral compressive; TFS, tibiofemoral shear.

forces than uninjured cyclists. ${ }^{18}$ This result is in conflict with the theory that decreasing saddle height would lead to a larger compressive force at the patellofemoral joint. ${ }^{1,2,12}$ However, data from Bini and Hume ${ }^{18}$ are also retrospective in nature, which suggest that cyclists with knee pain may have sought for bike fitting advice or that the saddle height has limited influence in patellofemoral pressure. The pressure between the patella and the femur is dictated by muscle forces (which increases at low saddle heights) and by contact areas between cartilages (which also increases in larger knee flexions - that is, low saddle heights). ${ }^{32}$ Therefore, there seems to be a plateau in patellofemoral pressure at saddle heights close to $100 \% \pm 4 \%$ of the trochanteric height to the floor. ${ }^{18}$ In addition, Wheeler et $\mathrm{al}^{20}$ did not observe consistent differences in internal/external rotation moments at the tibiofemoral joint, which was initially anticipated to increase the stress in the knee joint soft tissues (e.g., meniscus). Although largely considered as a trigger of knee injuries, a limited "float" (i.e., rotation) of the cleat in relation to the pedal could not lead to overuse knee injuries. Theoretically, by increasing the "float" between the cleat and the pedal, the rotation moments could be reduced at the knee joint. However, a prospective link between increased float and reductions in knee pain is lacking.
Expanding the horizon of overuse (non-traumatic) injuries in cycling, Dettori and Norvel ${ }^{11}$ indicated that only a few of the components of the bicycle could be associated to the likelihood of developing an overuse injury, none of them related to knee pain. Changes in saddle design and changing the inclination of the saddle (tilt) were tested as positive to reduce numbness at the perineum and low back pain, respectively. One of the potential reasons for the lack of association between bicycle configuration and knee pain is due to the distribution of forces among the various muscles of the lower limb. ${ }^{33}$ Many studies observed that changes in saddle height, for example, have different responses in terms of changes in ankle, knee, and hip angles. ${ }^{33}$ This has been hypothesized because the large number of muscles crossing the 3 main joints in the lower limb allow for innumerous combinations of activations and muscle forces. Therefore, cyclists riding with a low saddle height, for example, could change their ankle and/or hip angles (via changes in muscle activation and forces), which could then minimize the load transferred through the knee joint. This mechanism could then postpone the observed increases in knee loads only when opting for extremely low saddle heights. ${ }^{34}$

The rehabilitation of cyclists with knee pain or overuse injury requires a full understanding of the mechanism that 
triggers the overuse injury. In the case of the knee joint, it is difficult to establish conclusive recommendations because only a couple of patterns have been observed to differ between injured and uninjured cyclists. The medial projection of the knee and the changes in activation for the quadriceps and hamstrings muscles could indicate 2 main options. The first would involve an assessment of force and mobility for hip adductors and abductors, which could provide evidence of potential imbalance of a given muscle group. However, we must keep in mind that this is very speculative given there is a lack of evidence in this area. The second option would involve the assessment of activation of vastus medialis in relation to vastus lateralis, which could help controlling the position of the patella in relation to the femur. Although patients with delayed onset of vastus medialis could be more prone to develop or sustain anterior knee pain, the literature is not conclusive in this area. ${ }^{35}$ Therefore, treatment involving an enhanced activation of the vastus medialis should be a secondary option.

\section{Limitations}

This review was limited to some extent. The first limitation was the assessment of articles by authors from the same research group, which constrains the quality assessment to similar standards. An additional limitation was related to the quantity and quality of the studies. As previously discussed, no study used prospective designs to assess factors related to knee pain and injuries in cycling. Few studies included cyclists with existing knee pain or injury. Therefore, the conclusions of this systematic review are associated with the limitations of the evidence available. Future studies should be prospective in nature to understand the potential determinants of knee pain and injury in cyclists. The partition of the cohort by type of injury would then allow a more comprehensive understanding of how each component of the knee joint (e.g., patellofemoral) is affected by injury.

\section{Conclusion}

Cyclists with overuse-related pain or injuries in their knees present an increased medial projection of their knees and an altered activation of the vastus medialis and vastus lateralis muscles. However, this evidence is based on retrospective studies comparing cyclists with and without pain, which limits the conclusion on how cyclists develop knee pain and what are the main options for treatment of knee pain.

\section{Acknowledgment}

We thank the University for providing access to the search databases and software required to conduct this research.

\section{Author contributions}

All authors contributed toward data analysis, drafting and revising the paper and agree to be accountable for all aspects of the work.

\section{Disclosure}

The authors report no conflicts of interest in this work.

\section{References}

1. Callaghan MJ. Lower body problems and injury in cycling. J Bodywork Mov Ther. 2005;9(3):226-236.

2. Wanich T, Hodgkins C, Columbier J-A, Muraski E, Kennedy JG. Cycling injuries of the lower extremity. J Am Acad Orthop Surg. 2007;15(12):748-756

3. Althunyan AK, Darwish MA, Abdel Wahab MM. Knee problems and its associated factors among active cyclists in Eastern Province, Saudi Arabia. J Fam Community Med. 2017;24(1):23-29.

4. Bakkes ES, Hendry JA, Uys MS. The occurrence of cycling injuries in the western province: a descriptive study. South African J Physiother. 1993;49(4):61-65.

5. Clarsen B, Bahr R, Heymans MW, et al. The prevalence and impact of overuse injuries in five Norwegian sports: application of a new surveillance method. Scand J Med Sci Sports. 2015;25(3):323-330.

6. Clarsen B, Krosshaug T, Bahr R. Overuse injuries in professional road cyclists. Am J Sports Med. 2010;38(12):2494-2501.

7. Dahlquist M, Leisz M-C, Finkelstein M. The club-level road cyclist: injury, pain, and performance. Clin J Sport Med. 2015;25(2): $88-94$.

8. Dannenberg AL, Needle S, Mullady D, Kolodner KB. Predictors of injury among 1638 riders in a recreational long-distance bicycle tour: cycle across Maryland. Am J Sports Med. 1996;24(6):747-753.

9. van der Walt A, Janse van Rensburg DC, Fletcher L, Grant CC, van der Walt AJ. Non-traumatic injury profile of amateur cyclists. S Afr J Sports Med. 2014;26(4):119-122.

10. Weiss BD. Nontraumatic injuries in amateur long-distance bicyclists. Am J Sports Med. 1985;13(3):187-192.

11. Dettori NJ, Norvell DC. Non-traumatic bicycle injuries - a review of the literature. Sports Med. 2006;36(1):7-18.

12. Asplund C, St Pierre P. Knee pain and bicycling - fitting concepts for clinicians. Phys Sportsmed. 2004;32(4):23-30.

13. Silberman MR. Bicycling injuries. Cur Sports Med Rep. 2013;12(5): 337-345.

14. Sabeti-Aschraf M, Serek M, Geisler M, et al. Overuse injuries correlated to the mountain bike's adjustment: a prospective field study. Open Sports Sci J. 2010;3:1-6.

15. Agresta $\mathrm{C}$, Brown A. Gait retraining for injured and healthy runners using augmented feedback: a systematic literature review. J Orthop Sports Phys Ther. 2015;45(8):576-584.

16. Arnold MP, Baumann JU, Koch HG. Pelvic crural muscle contractures and femoropatellar pain syndrome in cyclists. Schweizerische Zeitschrift fur Sportmedizin. 1988;36(4):187-190.

17. Bailey MP, Maillardet FJ, Messenger N. Kinematics of cycling in relation to anterior knee pain and patellar tendinitis. J Sports Sci. 2003;21(8):649-657.

18. Bini RR, Hume PA. Effects of saddle height on knee forces of recreational cyclists with and without knee pain. Int SportMed J. 2014;15(2):188-199.

19. Dieter BP, McGowan CP, Stoll SK, Vella CA. Muscle activation patterns and patellofemoral pain in cyclists. Med Sci Sports Exerc. 2014;46(4):753-761.

20. Wheeler JB, Gregor RJ, Broker JP. The effect of clipless float design on shoe pedal interface kinetics and overuse injuries during cycling. J Appl Biomech. 1995;11(2):119-141. 
21. Moore W, Krabak BJ. Chronic lateral knee pain in a cyclist: popliteal artery entrapment. Clin J Sport Med. 2007;17(5):401-403.

22. Swart J, Tucker R, Lamberts RP, Albertus-Kajee Y, Lambert MI. Potential causes of chronic anterior knee pain in a former winner of the Tour de France. Int Sportmed J. 2008;9(4):162-171.

23. Bini RR, Hume PA, Lanferdini FJ, Vaz MA. Effects of moving forward or backward on the saddle on knee joint forces during cycling. Phys Ther Sport. 2013;14(1):23-27.

24. Farrell KC, Reisinger KD, Tillman MD. Force and repetition in cycling: possible implications for iliotibial band friction syndrome. Knee. 2003;10(1):103-109.

25. Gregersen CS, Hull ML, Hakansson NA. How changing the nnversion/ eversion foot angle affects the nondriving intersegmental knee moments and the relative activation of the vastii muscles in cycling. $J$ Biomech Eng. 2006;128(3):391-398.

26. Priego Quesada JI, Pérez-Soriano P, Lucas-Cuevas AG, Salvador Palmer R, Cibrián Ortiz de Anda RM. Effect of bike-fit in the perception of comfort, fatigue and pain. J Sports Sci. 2017;35(14):1459-1465.

27. Noehren B, Barrance PJ, Pohl MP, Davis IS. A comparison of tibiofemoral and patellofemoral alignment during a neutral and valgus single leg squat: an MRI study. Knee. 2012;19(4):380-386.
28. Willson JD, Kernozek TW, Arndt RL, Reznichek DA, Scott Straker J. Gluteal muscle activation during running in females with and without patellofemoral pain syndrome. Clin Biomech. 2011;26(7):735-740.

29. Bini RR, Carpes FP, Diefenthaeler F. Influencia da pedalada com os joelhos tangenciando o quadro da bicicleta sobre a ativacao dos musculos do membro inferior. Rev Bras Educ Fisi Esp. 25(1):27-37.

30. Bini RR, Carpes FP, Diefenthaeler F. Effects of knee frontal plane position on pedal forces during cycling: a preliminary study. Braz $J$ Kinanthrop Hum Perf. 2009;11(2):142-149.

31. Ericson MO, Nisell R, Ekholm J. Varus and valgus loads on the knee joint during ergometer cycling. Scand J Med Sci Sports. 1984;6(2):39-45.

32. Salsich GB, Ward SR, Terk MR, Powers CM. In vivo assessment of patellofemoral joint contact area in individuals who are pain free. Clin Orthop Rel Res. 2003(417):277-284.

33. Bini MR, Hume PA, Croft JL. Effects of bicycle saddle height on knee injury risk and cycling performance. Sports Med. 41(6):463-476.

34. Ericson MO, Nisell R. Patellofemoral joint forces during ergometric cycling. Phys Ther. 1987;67(9):1365-1369.

35. Chester R, Smith TO, Sweeting D, Dixon J, Wood S, Song F. The relative timing of VMO and VL in the aetiology of anterior knee pain: a systematic review and meta-analysis. BMC Musculoskeletal Dis. 2008;9.
Open Access Journal of Sports Medicine

\section{Publish your work in this journal}

The Open Access Journal of Sports Medicine is an international, peer-reviewed, open access journal publishing original research, reports, reviews and commentaries on all areas of sports medicine. The journal is included on PubMed. The manuscript management system is completely online and includes a very quick and fair
Dovepress

peer-review system. Visit http://www.dovepress.com/testimonials.php to read real quotes from published authors. 